\title{
Static body postural misalignment in individuals with temporomandibular disorders: a systematic review
}

\author{
Thaís C. Chaves ${ }^{1}$, Aline M. Turci², Carina F. Pinheiro², \\ Letícia M. Sousa ${ }^{3}$, Débora B. Grossi ${ }^{2}$
}

\begin{abstract}
Background: The association between body postural changes and temporomandibular disorders (TMD) has been widely discussed in the literature, however, there is little evidence to support this association. Objectives: The aim of the present study was to conduct a systematic review to assess the evidence concerning the association between static body postural misalignment and TMD. Method: A search was conducted in the PubMed/Medline, Embase, Lilacs, Scielo, Cochrane, and Scopus databases including studies published in English between 1950 and March 2012. Cross-sectional, cohort, case control, and survey studies that assessed body posture in TMD patients were selected. Two reviewers performed each step independently. A methodological checklist was used to evaluate the quality of the selected articles. Results: Twenty studies were analyzed for their methodological quality. Only one study was classified as a moderate quality study and two were classified as strong quality studies. Among all studies considered, only 12 included craniocervical postural assessment, 2 included assessment of craniocervical and shoulder postures,, and 6 included global assessment of body posture. Conclusion: There is strong evidence of craniocervical postural changes in myogenous TMD, moderate evidence of cervical postural misalignment in arthrogenous TMD, and no evidence of absence of craniocervical postural misalignment in mixed TMD patients or of global body postural misalignment in patients with TMD. It is important to note the poor methodological quality of the studies, particularly those regarding global body postural misalignment in TMD patients.
\end{abstract}

Keywords: temporomandibular disorders; body posture; craniocervical posture; systematic review.

HOW TO CITE THIS ARTICLE

Chaves TC, Turci AM, Pinheiro CF, Sousa LM, Grossi DB. Static body postural misalignment in individuals with temporomandibular disorders: a systematic review. Braz J Phys Ther. 2014 Nov-Dec; 18(6):481-501. http://dx.doi.org/10.1590/ bjpt-rbf.2014.0061

\section{Introduction}

Temporomandibular Disorder (TMD) is a set of disorders characterized by signs and symptoms involving the temporomadibular joints and mastication muscles, as well as related structures ${ }^{1}$. There is evidence that its etiology is multifactorial and include psychological, biomechanical, and neurophysiological factors ${ }^{2-4}$.

The association between body postural changes and TMD has been widely discussed in the literature ${ }^{5-19}$. It is believed that in biomechanical terms, changes in head posture may be associated with the development and/or perpetuation of $\mathrm{TMD}^{20}$. Several studies over the last decades have reported the Forward Head Position (FHP) in patients with TMD ${ }^{6,12,20,21}$, however, these changes have not been verified in many other studies $^{5,8,11,22}$.

Craniocervical posture is only one of the body segments that must be considered for postural assessment, specifically because adjacent postural compensations are expected in other segments considering that muscle chains are interconnected ${ }^{23,24}$.

Three systematic reviews regarding the theme were found in the literature ${ }^{20,25,26}$, however, the reviews by Olivo et al. ${ }^{20}$ and Rocha et al. ${ }^{26}$ only considered studies related to craniocervical posture and TMD, and the review by Perinetti and Contardo ${ }^{25}$ did not include studies on craniocervical posture. Moreover, this review ${ }^{25}$ classified, in the same list,

\footnotetext{
${ }^{1}$ Departamento de Neurosciências e Ciências do Comportamento, Faculdade de Medicina de Ribeirão Preto (FMRP), Universidade de São Paulo (USP), Ribeirão Preto, SP, Brazil

${ }^{2}$ Departamento de Biomecânica, Medicina e Reabilitação do Aparelho Locomotor, FMRP, USP, Ribeirão Preto, SP, Brazil

${ }^{3}$ Departamento de Medicina Social, FMRP, USP, Ribeirão Preto, SP, Brazil

Received: 10/15/2013 Revised: 04/16/2014 Accepted: 06/04/2014
} 
studies regarding stabilometry (i.e. postural balance assessment) and static posture. Therefore, there was no systematic review available in the present literature involving body postural alterations (either segmentary or global) in individuals with TMD. Given the great interest in the theme and the poor methodological quality of the studies about body postural misalignment and the postural assessment methods employed in these studies ${ }^{20,25}$, it was important to carry out a study that analyzed real evidence of associations between static postural changes and TMD in order to guide better controlled studies in the future.

The confirmation of the evidence of the association between craniocervical or body postural misalignment and TMD may help to determine the predisposing and/or perpetuating factors in the development of TMD and guide new and well designed research to confirm this association. Moreover, some studies have demonstrated the relief of TMD symptoms after treatment involving postural reeducation ${ }^{27,28}$.

It was expected that the findings of this systematic review would demonstrate whether the evidence available was sufficient to indicate an association between body postural misalignment and TMD and/ or subtypes. Thus, the aim of this study was to review the literature available on the main databases (i.e. PubMed/Medline, Embase, Lilacs, Scielo, Cochrane, and Scopus) about body postural misalignment in patients with TMD and subtypes.

\section{Method}

\section{Data sources}

In order to find studies examining the relationship between static body posture and TMD, bibliographical surveys were performed in the following databases: PubMed/Medline, Embase, Lilacs, Scielo, Cochrane, and Scopus. PRISMA ${ }^{29}$ (Preferred Reporting Items for Systematic reviews and Meta-Analyses) guidelines were followed.

The search comprised only studies in English published between 1950 and March 2012. The search terms were:

1) temporomandibular disorders

2) myofascial pain

3) stomatognathic system

4) craniofacial disorders

AND

1) body posture
2) head posture

3) body posture assessment

4) posture

Searches were performed by the same researcher. The limits of databases were selected when the option was available. In the Embase and Pubmed databases, the limits followed were: Published: 1966 to March 2012, quick limits: humans, only in English, article in press.

\section{Eligibility criteria}

Types of Studies. i) cohort/case-control studies; and ii) cross-sectional and survey studies. Publications such as case reports, case series, reviews, and opinion articles were excluded. As the main objective of this study was to verify the possible association between TMD and body postural changes, randomized controlled clinical trials were excluded, since these studies are used to verify the effectiveness of an intervention and, therefore, not adequate to verify relationships between variables.

Participants. Inclusion was restricted to studies using human participants who (i) were between 7 and 60 years of age; (ii) had been diagnosed with TMD; (iii) had not previously had TMJ surgery; (iv) had no history of trauma or fracture in the TMJ or craniomandibular system; and, (v) had no other serious comorbid conditions (e.g. cancer, rheumatic disease, neurological problems).

Types of Outcome Measures. The following methods of body postural assessment were considered: body landmarks, visual inspection, pictures or radiographs.

\section{Data collection}

The reviewers analyzed all studies initially selected by the title or abstract for the inclusion/ exclusion criteria. The published studies had to provide enough information to meet the inclusion criteria and not be eliminated by the exclusion criteria. In order for studies to be evaluated at the next level (critical appraisal), the study had to meet all of the inclusion criteria. When the reviewers disagreed on whether a study met a criterion, rating forms (form containing the Critical Appraisal completed by each reviewer-Table 1) were compared, and the criterion was discussed until a consensus was reached.

As recommended by PRISMA ${ }^{29}$, the studies were selected by the title, abstract, and full text. Two independent reviewers screened the abstracts of the publications found in the databases. 
Table 1. Critical appraisal form used to evaluate included studies. Based on the paper by Olivo et al. ${ }^{20}$.

\section{Criteria for review and methodological quality assessment}

1) Type of Study
a) Randomized Clinical Trial and Random / Cohort
S
b) Pre-experimental / Non-randomized Clinical Study
$\mathrm{M}$
c) Case Control/ Cross-Sectional

2) Diagnostic Criteria/Patients Assessment
a) RDC/TMD Diagnostic
b) American Academy of Orofacial Pain (AAOP) Criteria/Image
c) Another Tool - Questionnaire
d) Complaint or report
e) Description of the groups: Myogenous / Arthrogenous / Mixed
$\mathrm{S}=4 / \mathrm{M}=3 / \mathrm{W}<2$

4

3

2

3) Volunteer Agreement
a) $>80 \%$ $\mathrm{S}$
b) 60 to $80 \%$ $\mathrm{M}$
c) $<60 \%$ W
d) Cannot answer

4) Sample Size Calculation

a) Appropriate / A priori effect size and power $\quad \mathrm{S}$ b) Small, justification provided $\quad \mathrm{M}$ c) Small and no justification provided $\quad$ W

\section{5) Method}

a) Visual Inspection - live Prior training of examiners Intrarater reliability Interrater reliability Reproducibility / Error Analysis Validity / Sensitivity / Specificity Well described

b) Qualitative Photographic Analysis Prior training of examiners Intrarater reliability Interrater reliability Reproducibility / Error Analysis Validity / Sensitivity / Specificity Well described

c) Quantitative Photographic Analysis

Prior training of examiners Intrarater reliability Interrater reliability Reproducibility / Error Analysis Validity / Sensitivity / Specificity Well described

d) Radiography/Cephalometry Prior training of examiners Intrarater reliability Interrater reliability Reproducibility / Error Analysis Validity / Sensitivity / Specificity Well described
NA

NA

NA

NA

NA

NA

NA

NA

NA

NA

NA

NA

NA 
Table 1. Continued...

\section{Criteria for review and methodological quality assessment}

For each item:

$\mathrm{S}=5$ to 7 points $/ \mathrm{M}=4$ to $3 / \mathrm{W}<2$

NOTE: If an item was classified as NA (not applicable), it shoud be classified as follows: 0 to

$33 \%$ of the items classified as NA $=\mathrm{W} / 34$ to $66 \%=\mathrm{M} / 67$ to $100 \%=\mathrm{S}$

6) Blinding

Patients

Examiner of the experiment

Examiner the measure

$\mathrm{S}=2$ or $3 / \mathrm{M}=1 / \mathrm{W}=0$

7) External validity

Internal validity

Good experimental design / selection bias

Good control of confounding factors

Appropriate statistical and sample calculation

Consistency in results (validity / reliability / sensitivity)

( 1 point only if the paper achieve all items described)

The results have clinical relevance

Patients are representative of the population / where screened / age / comorbidities / severity

Observed aspects were clarified in the conclusion and discussion

$\mathrm{S}=4$ or $3 / \mathrm{M}=2 / \mathrm{W}=1$ or 0

8) Adequate statistical analysis

a) Appropriate /suitable statistical tests

b) Precision (P value described)

c) Confidence Interval

$\mathrm{S}: 2 / \mathrm{M}: 1 / \mathrm{W}: 0$

$\mathrm{S}=$ Strong; $\mathrm{M}=$ Moderate; $\mathrm{W}=$ Weak; NA: Not applicable.

\section{Quality evaluation}

In order to document the internal and external validity of the studies, a modified quality evaluation instrument was applied ${ }^{20,30}$. This tool considered: 1- study design, 2- control of confounding variables, 3- subjects' agreement to participate, 4- sample size calculation, 5- validity/reliability of outcomes measurements, 6- blinding, 7- external validity, and 8 - statistical analysis (Table 1). Two independent reviewers evaluated the studies based on specific determined criteria. If there was inadequate information in the published papers to allow evaluation of the criteria, the authors of the studies were contacted to clarify study design and specific characteristics of the study. If the authors did not reply, the studies were evaluated with the information available.
Each evaluated study item was then given a grade of strong (S), moderate (M) or weak (W) in each category. The rating system was based on a similar procedure $^{20,31}$. Critical appraisal was completed independently by the two reviewers, and their results were compared. Data were extracted from each article without blinding of the authors. Finally, every study was graded depending on the following criteria (Table 1):

- STRONG - Strong for items: 2, 4, 5, 6, 7, and 8 or Moderate or Strong for items 1 and 3;

- MODERATE - Moderate for the following items: 2, 4, 5, 6, 7, and 8 and Weak or Moderate for items 1 and 3 ;

- WEAK - Weak for at least one of the items: 2 , $4,5,6,7$, and 8 . 


\section{Statistical analysis}

The kappa coefficient test was used to verify the agreement between both reviewers before the consensus stage in the analysis of studies. Results were obtained using the weighted kappa coefficient and analyzed using SPSS version 17, and the agreement was classified as follows: $\mathrm{K}<0.20$ (poor), 0.21 to 0.40 (weak), 0.41 to 0.60 (moderate), 0.61 to 0.80 (good), 0.81 to 1.0 (excellent).

\section{Results}

The selection included 1067 studies (271 in Pubmed, 3 in Scielo, 703 in Scopus, 33 in Lilacs, and 57 in Embase) considering duplicates/triplicates. After the removal of duplicates among different databases, 393 studies remained. After comparison for the existence of duplicates in the same database, 348 studies remained. The studies were screened again by verifying the title, and only 36 studies were selected.
Nevertheless, 16 studies were initially excluded after the abstract analysis based on the following inclusion and exclusion criteria : i) studies involving therapeutic intervention ${ }^{28,32-35}$; ii) sample eligibility criteria were not met (patients with TMD) ${ }^{35-38}$; iii) studies involving static balance assessment (stabilometry) or not involving static postural assessment ${ }^{39-41}$; and iv) non-experimental studies (i.e. letters to the editor, narrative literature reviews, pilot studies $)^{42-45}$.

After analysis of the abstracts, all 20 studies were read once in full and five studies were excluded adopting the criteria previously defined. The studies were excluded because they consisted of: i) nonexperimental studies ${ }^{46,47}$; ii) a study involving therapeutic intervention ${ }^{27}$; iii) a study involving static postural assessment ${ }^{48}$; and 4) a study with inappropriate sample eligibility criteria ${ }^{49}$.

At the end of the process, through the selection by full text, a total of 15 studies were considered ${ }^{5-19}$. Later, 5 more studies were included through manual search ${ }^{21,22,50-52}$. Therefore, 20 studies in

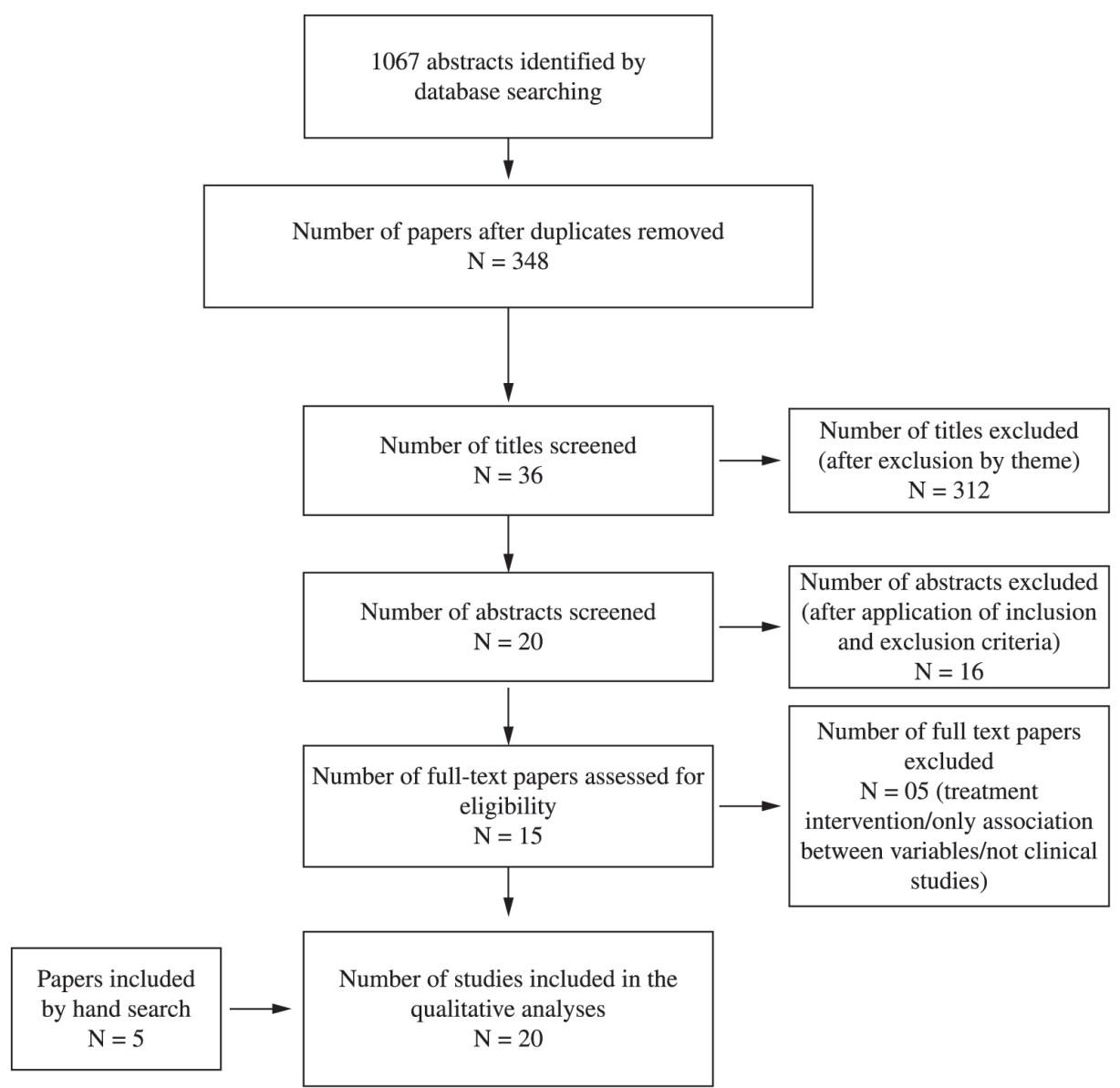

Figure 1. Flow diagram through the different phases of the systematic review as recommended by the PRISMA statement ${ }^{30}$. 
total were reviewed in the present study. All stages of this process are described in Figure 1.

The agreement between both reviewers for the final classification of the 20 studies obtained Interrater Kappa of 0.90 (Confidence Interval 95\%: 0.73-1), demonstrating an excellent level of agreement between them.

\section{Quality criteria score}

Considering the criteria for assessment of methodological quality, only three studies were classified as moderate ${ }^{51}$ or strong ${ }^{19,21}$. The main methodological problems observed were: 1) absence of description regarding sample size calculation ${ }^{5-18,49,50}$ ( $\mathrm{n}=15$ studies); 2$)$ absence of reliability description of measures or validity of the method employed ${ }^{5,6,12,14,17,18,50}$ ( $\mathrm{n}=7$ studies); 3) absence of blinding of the examiners $^{6,7,10-12,14,17,50,53}$ ( $\mathrm{n}=9$ studies); and, 4) non-compliance with criteria for internal and external validity $6,7,10,11,13-15,18,52$ ( $\mathrm{n}=9$ studies). Moreover, the randomization procedure for sample selection, which was observed in only six studies ${ }^{5,13,14,16,22}$, was still a significant bias that hindered the quality of the studies found in the literature ${ }^{20}$ (Table 2).

Table 2. Methodological scoring of the articles included in the review.

\begin{tabular}{|c|c|c|c|c|c|c|c|c|c|}
\hline \multicolumn{10}{|c|}{ Items / Score* } \\
\hline Studies & 1 & 2 & 3 & 4 & 5 & 6 & 7 & 8 & Rating \\
\hline \multicolumn{10}{|c|}{ Craniocervical posture } \\
\hline Braun $^{6}$ & $\mathrm{~W}$ & $\mathrm{~W}$ & $\mathrm{~W}$ & $\mathrm{~W}$ & $\mathrm{~W}$ & $\mathrm{~W}$ & W & $\mathrm{S}$ & WEAK \\
\hline Hackney et al. ${ }^{11}$ & $\mathrm{~W}$ & $\mathrm{~S}$ & W & W & W & W & W & S & WEAK \\
\hline Lee et al. ${ }^{50}$ & W & W & $\mathrm{W}$ & $\mathrm{W}$ & W & M & $\mathrm{S}$ & $\mathrm{S}$ & WEAK \\
\hline Evcik and Aksoy ${ }^{12}$ & W & $\mathrm{S}$ & W & W & W & W & M & S & WEAK \\
\hline Sonnensen et al. ${ }^{10}$ & W & W & $\mathrm{S}$ & W & $\mathrm{S}$ & W & W & $\mathrm{S}$ & WEAK \\
\hline Visscher et al. ${ }^{8}$ & $\mathrm{~W}$ & M & $\mathrm{S}$ & $\mathrm{W}$ & $\mathrm{S}$ & $\mathrm{S}$ & $\mathrm{S}$ & $\mathrm{S}$ & WEAK \\
\hline D'Attilio et al. ${ }^{51}$ & $\mathrm{~W}$ & $\mathrm{~S}$ & $\mathrm{~S}$ & M & M & $\mathrm{S}$ & M & $\mathrm{S}$ & MODERATE \\
\hline Munhoz et al. ${ }^{13}$ & W & $\mathrm{S}$ & $\mathrm{S}$ & $\mathrm{W}$ & W & M & W & $\mathrm{S}$ & WEAK \\
\hline Ioi et al. ${ }^{52}$ & $\mathrm{~W}$ & S & $\mathrm{S}$ & S & M & W & W & $\mathrm{S}$ & WEAK \\
\hline Iunes et al..$^{22}$ & $\mathrm{~W}$ & $\mathrm{~S}$ & $\mathrm{~S}$ & $\mathrm{~W}$ & M & M & M & M & WEAK \\
\hline Matheus et al. ${ }^{15}$ & $\mathrm{~W}$ & $\mathrm{~S}$ & $\mathrm{~S}$ & $\mathrm{~W}$ & $\mathrm{~S}$ & $\mathrm{~S}$ & W & $\mathrm{S}$ & WEAK \\
\hline De Farias Neto et al. ${ }^{18}$ & W & $\mathrm{S}$ & $\mathrm{S}$ & $\mathrm{W}$ & W & $\mathrm{S}$ & W & $\mathrm{S}$ & WEAK \\
\hline Armijo-Olivo et al. ${ }^{19}$ & $\mathrm{~W}$ & $\mathrm{~S}$ & $\mathrm{~S}$ & $\mathrm{~S}$ & $\mathrm{~S}$ & $\mathrm{~S}$ & $\mathrm{~S}$ & $\mathrm{~S}$ & STRONG \\
\hline Armijo-Olivo et al. ${ }^{21}$ & W & $\mathrm{S}$ & $\mathrm{S}$ & S & $\mathrm{S}$ & $\mathrm{S}$ & $\mathrm{S}$ & $\mathrm{S}$ & STRONG \\
\hline \multicolumn{10}{|c|}{ Global Body posture } \\
\hline Darlow et al. ${ }^{5}$ & W & $\mathrm{W}$ & W & $\mathrm{W}$ & W & M & M & $\mathrm{S}$ & WEAK \\
\hline Zonnernberg et al. ${ }^{7}$ & $\mathrm{~W}$ & S & S & M & M & W & W & M & WEAK \\
\hline Nicolakis et al. ${ }^{9}$ & $\mathrm{~W}$ & $\mathrm{~W}$ & $\mathrm{~W}$ & $\mathrm{~W}$ & M & M & M & $\mathrm{S}$ & WEAK \\
\hline Munhoz et al. ${ }^{14}$ & W & $\mathrm{S}$ & S & W & W & W & W & $\mathrm{S}$ & WEAK \\
\hline Munhoz et al. ${ }^{16}$ & W & W & S & W & M & $\mathrm{S}$ & M & $\mathrm{S}$ & WEAK \\
\hline Saito et al. ${ }^{17}$ & $\mathrm{~W}$ & $\mathrm{~S}$ & S & $\mathrm{W}$ & W & W & M & M & WEAK \\
\hline \multirow{3}{*}{ Total Score } & $\mathrm{W}=20$ & $W=6$ & $\mathrm{~W}=6$ & $\mathrm{~W}=15$ & $\mathrm{~W}=9$ & $\mathrm{~W}=8$ & $\mathrm{~W}=9$ & $\mathrm{~W}=0$ & \\
\hline & $\mathrm{M}=0$ & $M=1$ & $M=1$ & $M=2$ & $M=6$ & $M=5$ & $M=7$ & $M=3$ & \\
\hline & $\mathrm{S}=0$ & $\mathrm{~S}=13$ & $\mathrm{~S}=13$ & $\mathrm{~S}=3$ & $\mathrm{~S}=5$ & $\mathrm{~S}=7$ & $S=4$ & $S=17$ & \\
\hline
\end{tabular}

$\mathrm{S}=$ Strong; M=Moderate; W=Weak; *1- Types of studies; 2 - Diagnostic criteria; 3 - Volunteer agreement; 4 - Sample size; 5 - Method; 6 - Examiner blinding; 7 - External validity; 8 - Statistical analyses. 


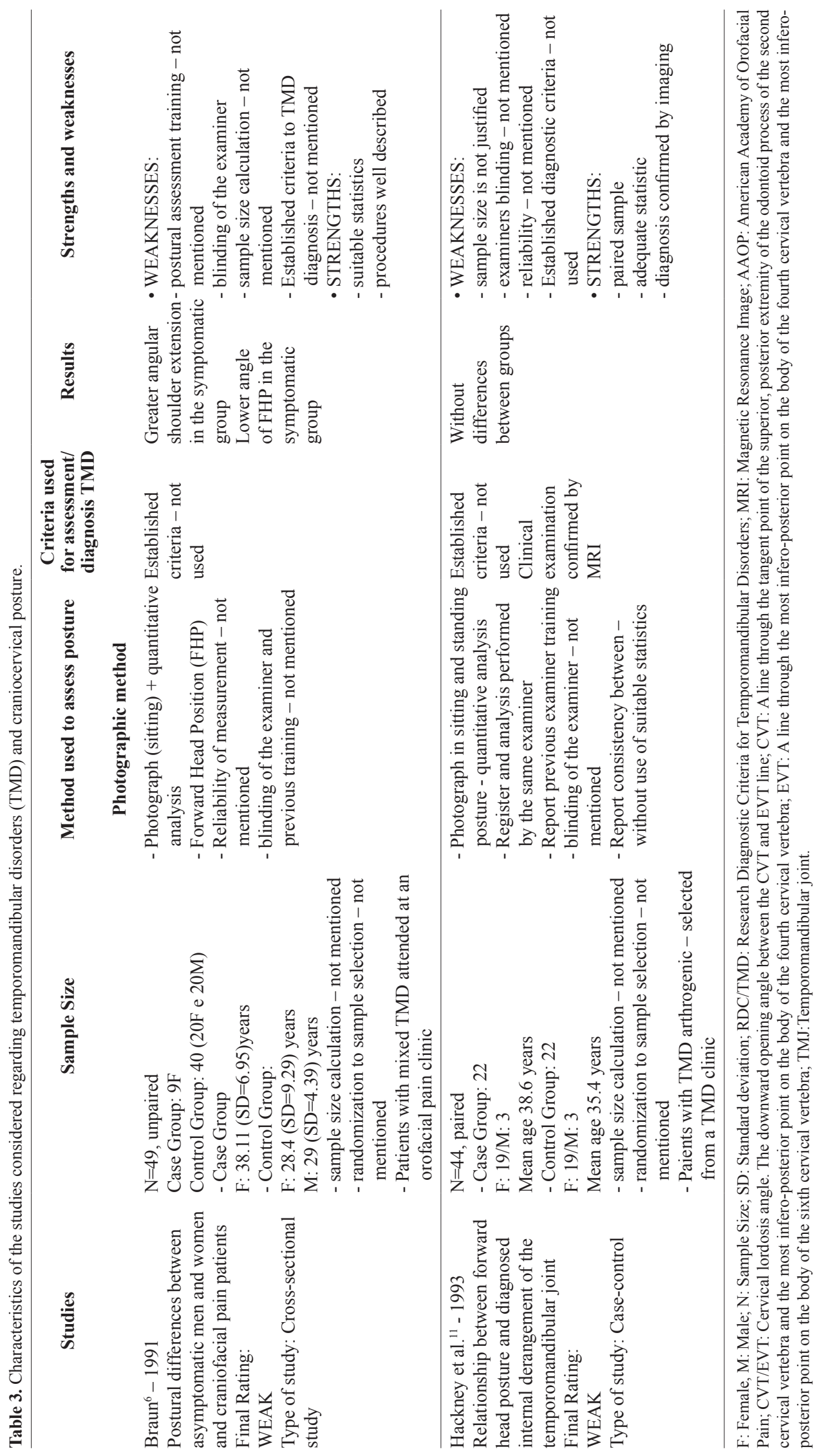



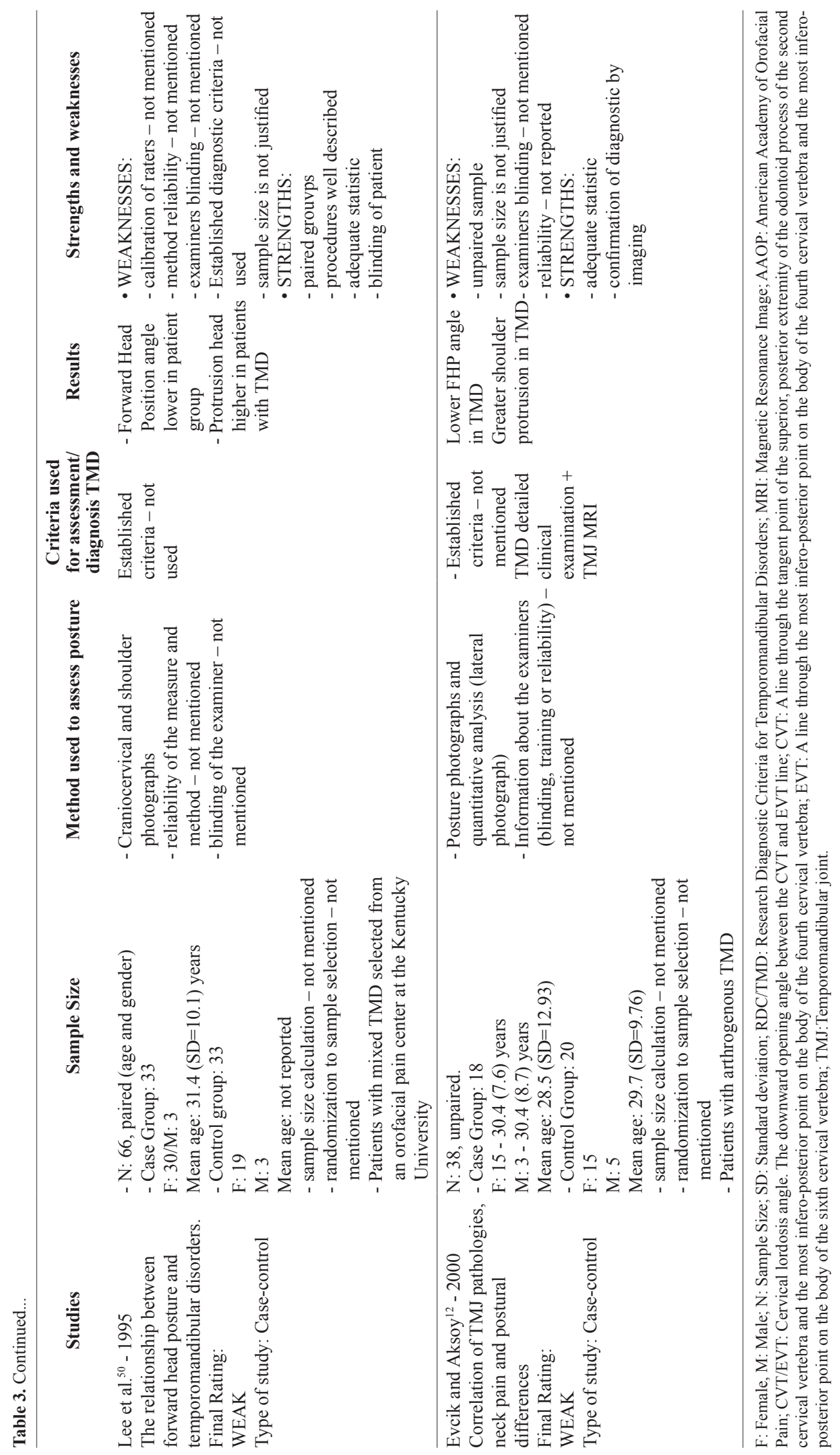

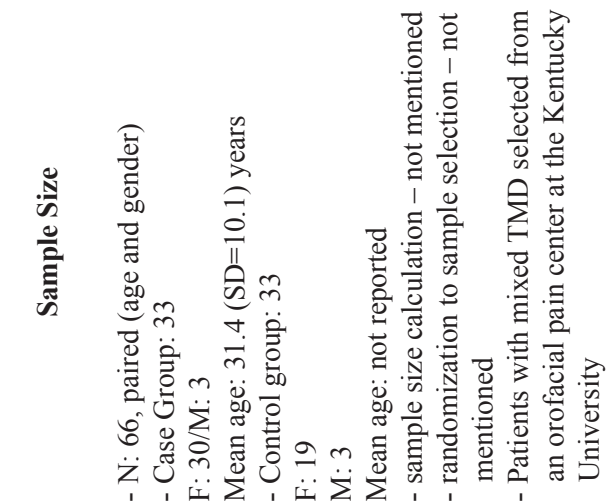
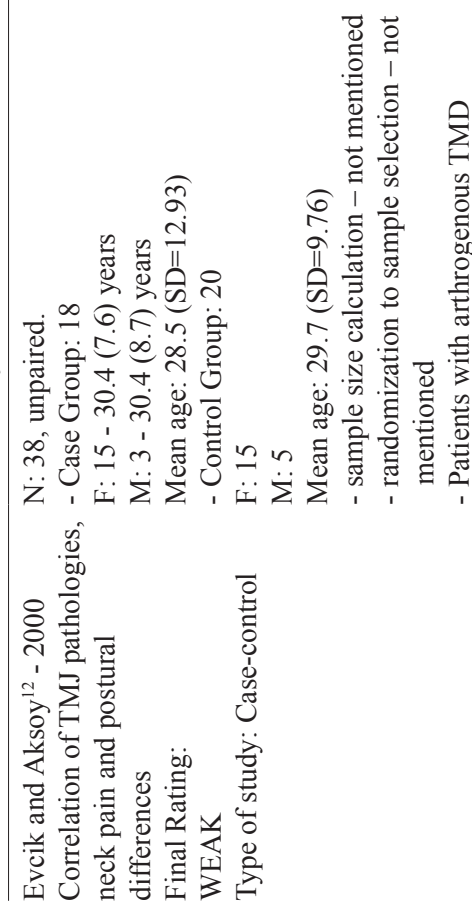


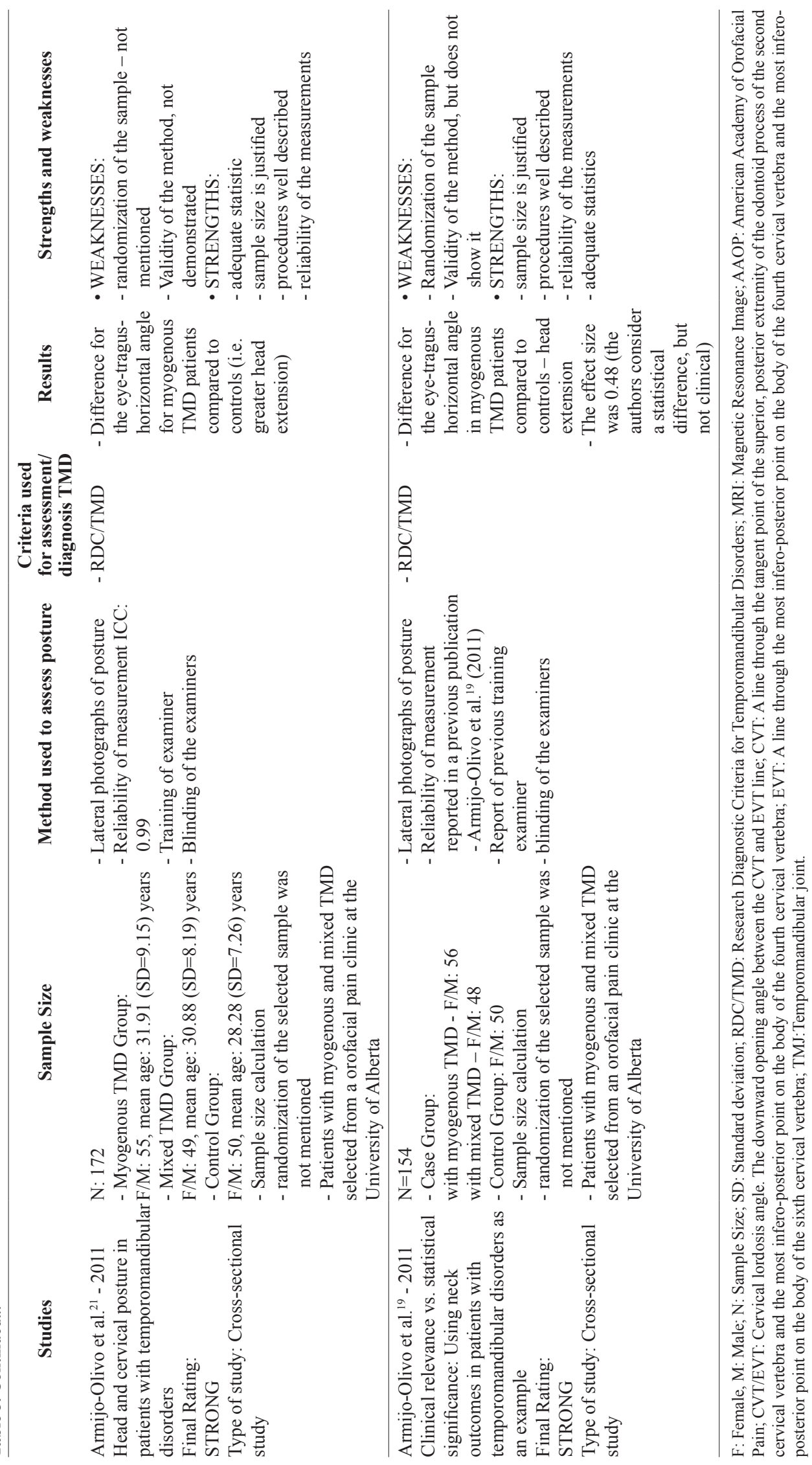




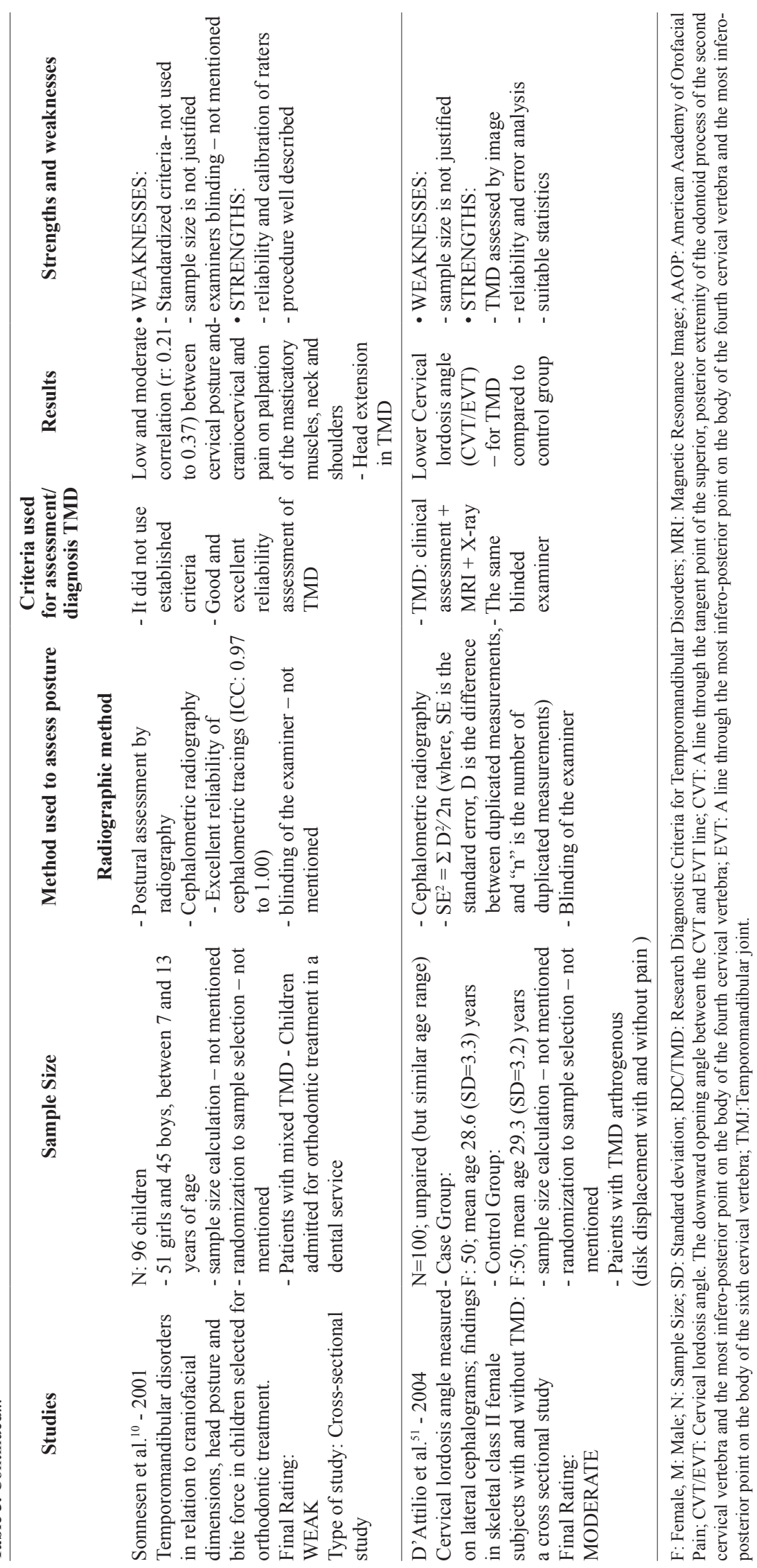




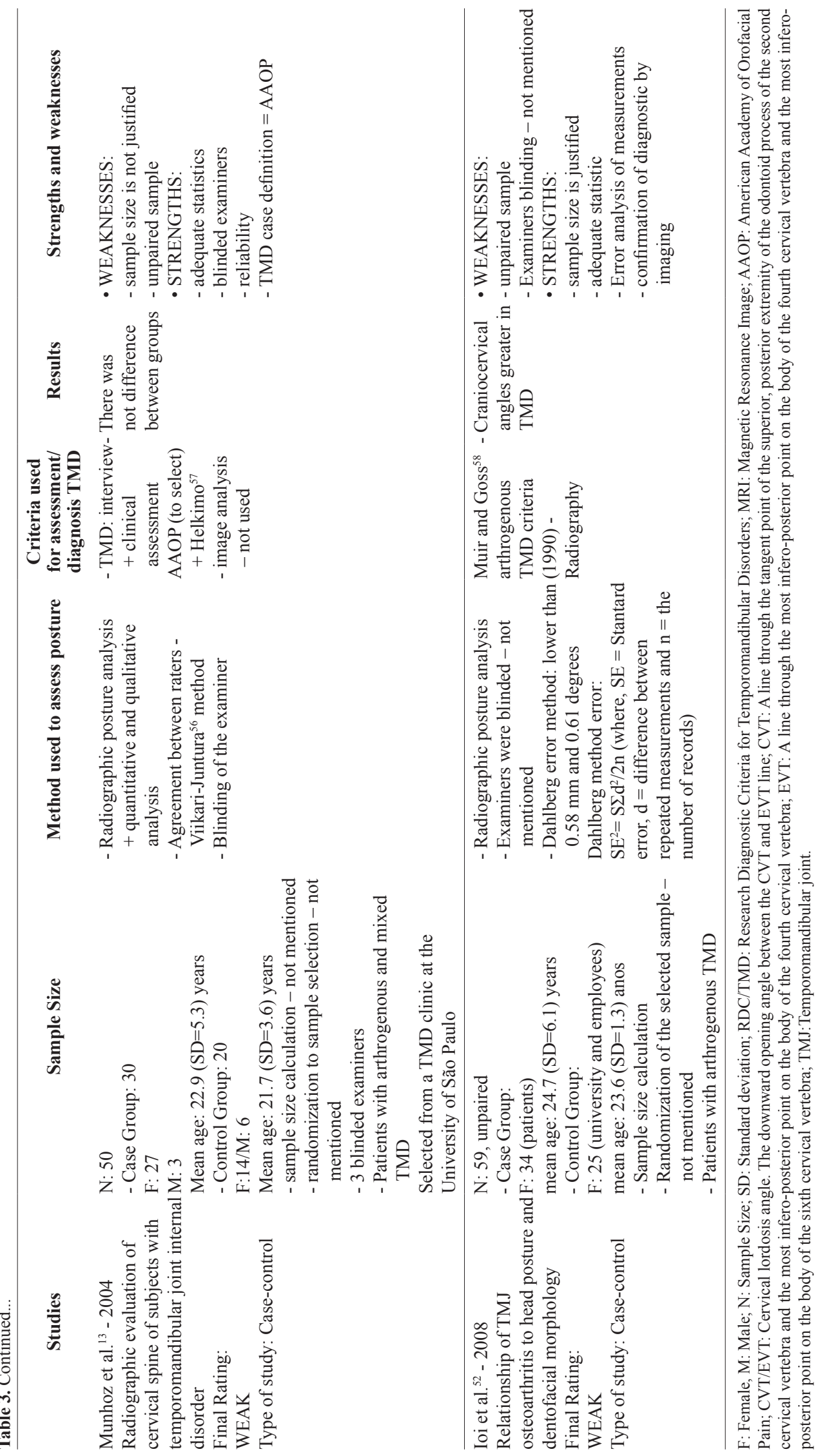




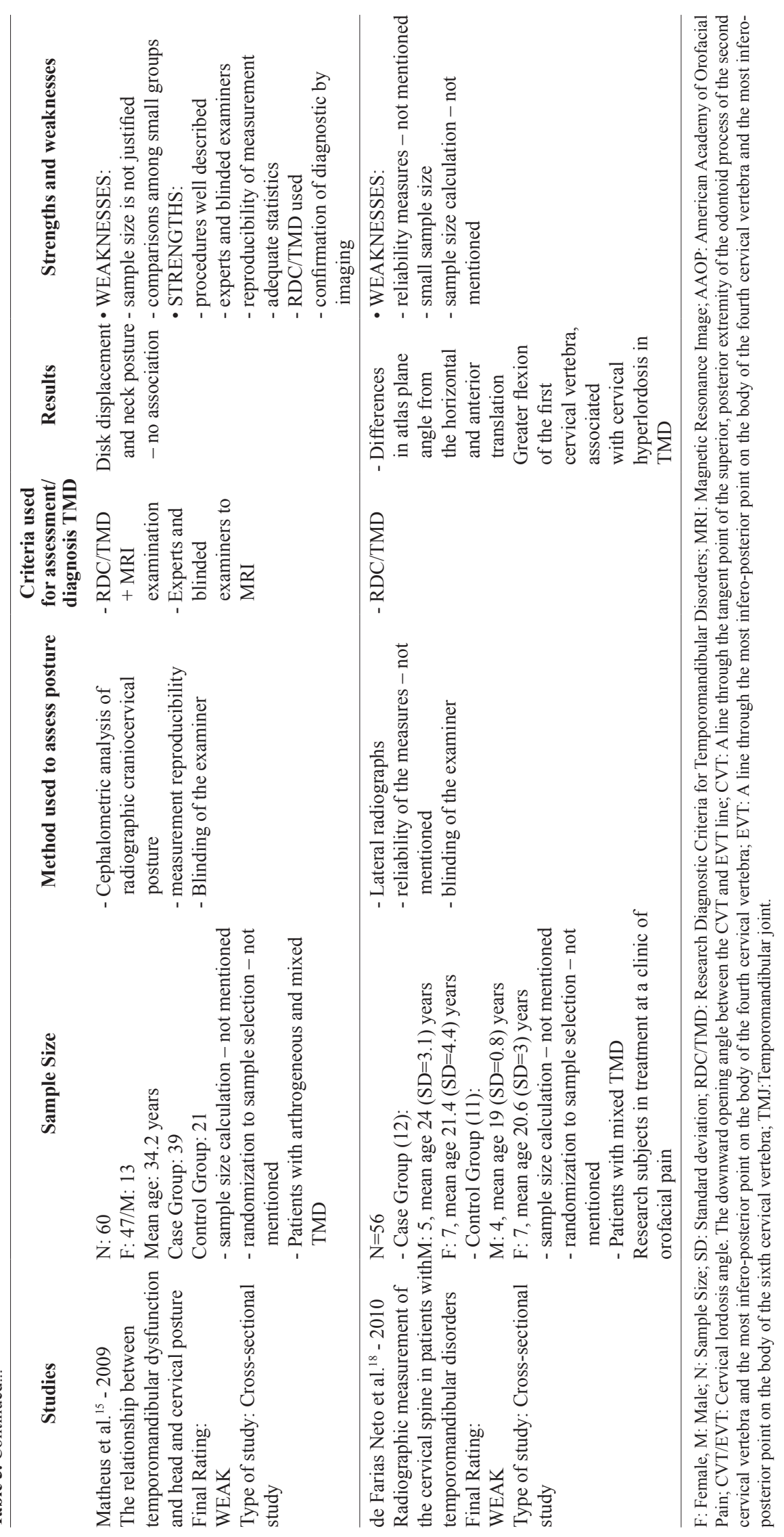



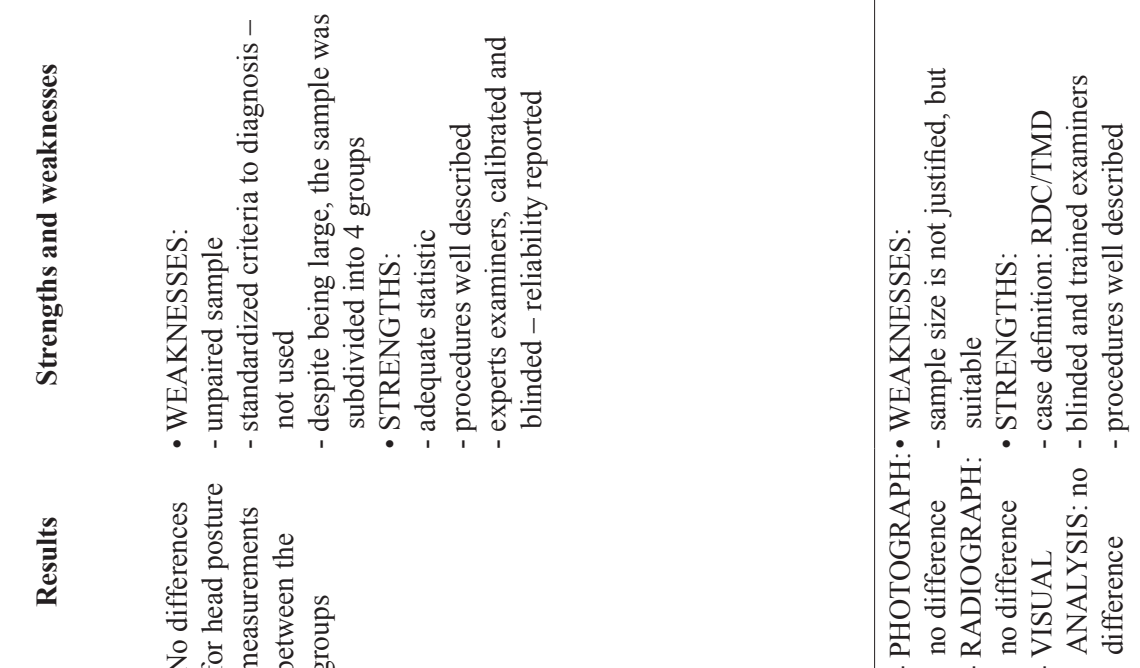

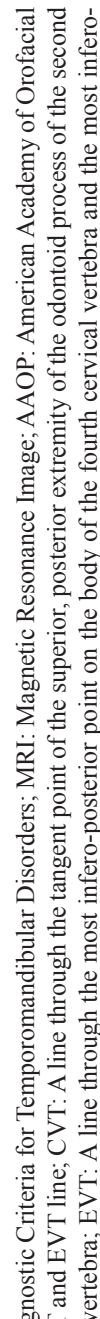

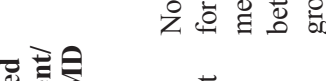

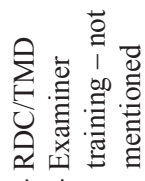

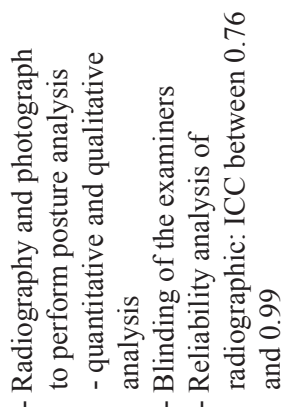




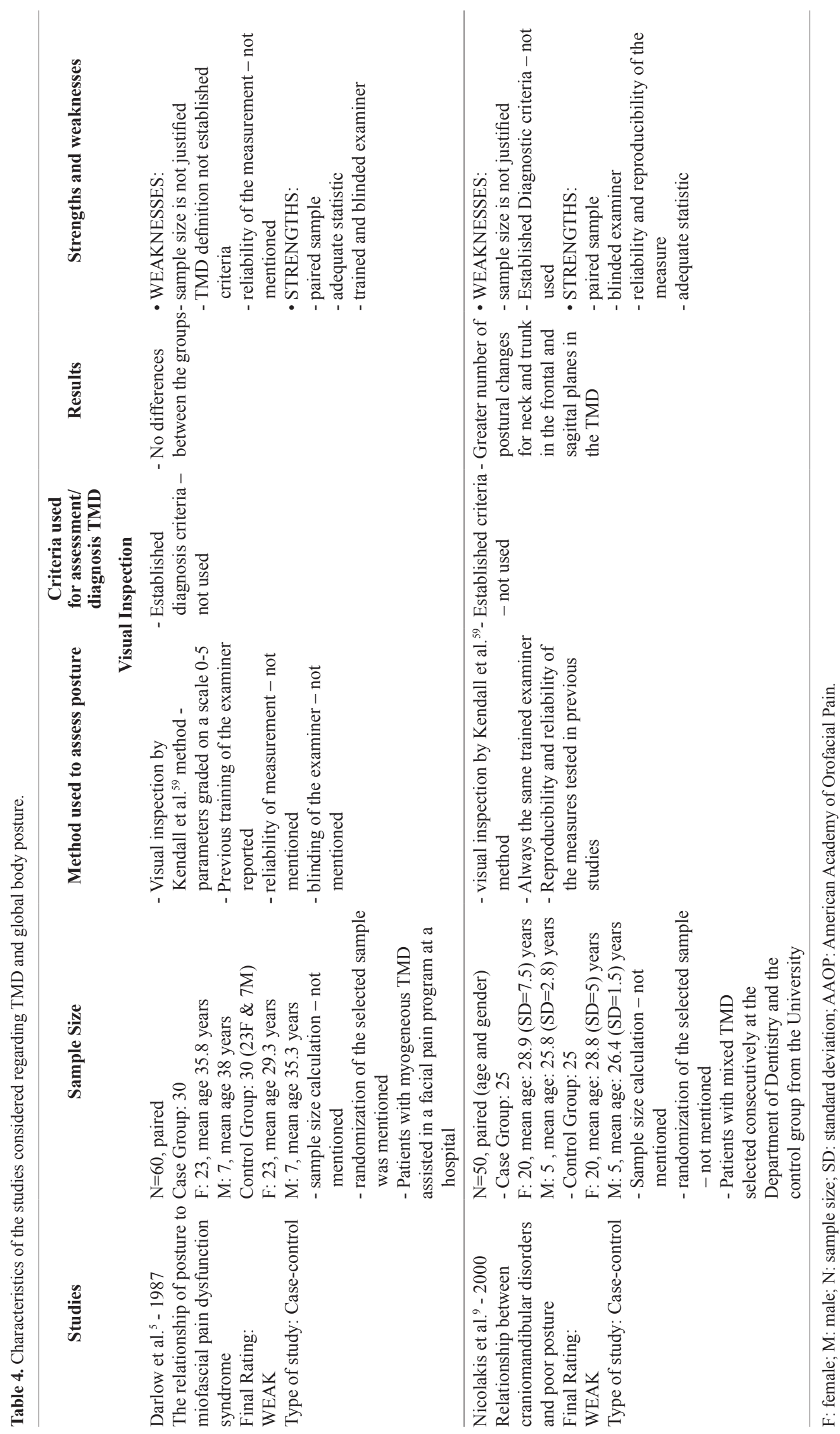




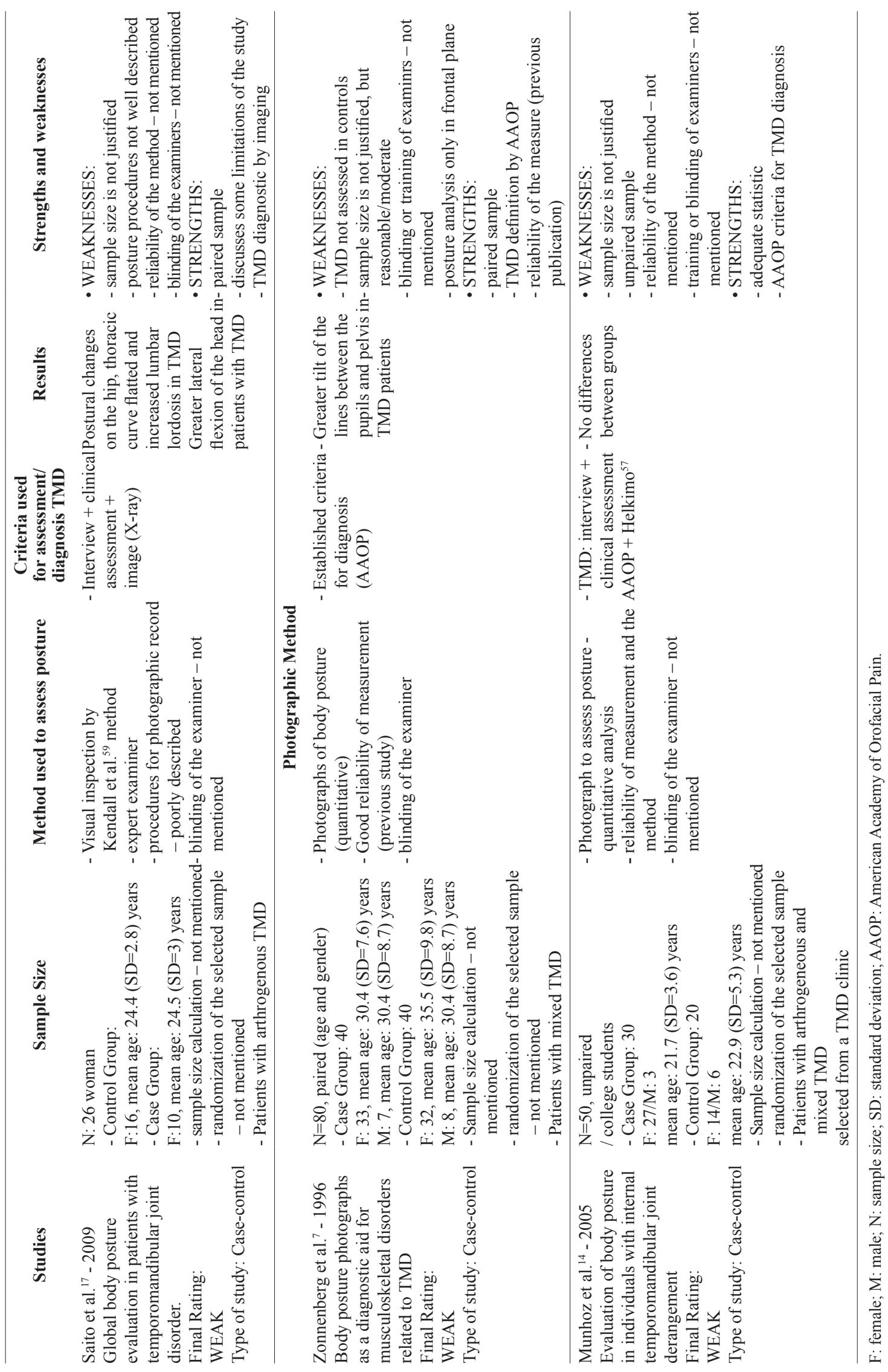




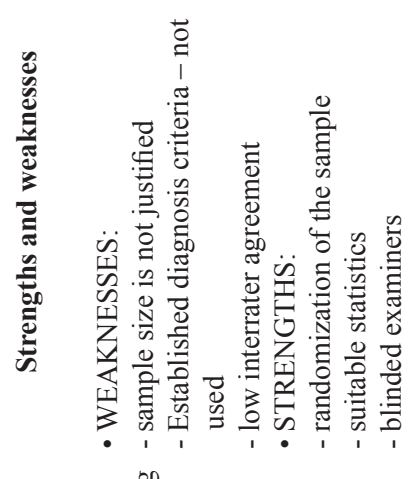

\section{Type of studies}

Of all 20 studies considered, 12 studies were classified as case-control ${ }^{5,7,9,11-14,16,17,22,50,52}$ and eight were classified as cross-sectional ${ }^{6,8,10,15,18,19,21,51}$. Only three studies used random sampling in the process of group selection ${ }^{5,14,16}$ (Tables 3 and 4).

\section{TMD assessment/Diagnosis criteria}

Seven studies used diagnosis criteria that are not well established in the literature ${ }^{5,6,9,10,12,16,50}$. Image analysis were employed in four studies ${ }^{11,17,51,52}$, the criterion of the American Academy of Orofacial Pain (AAOP) in three studies ${ }^{7,13,14}$, and the Research Diagnostic Criteria for Temporomandibular Disorders (RDC/TMD) ${ }^{3,4}$ in five studies ${ }^{15,18,19,21,22}$ (Tables 3 and 4).

\section{Segmental or global body postural assessment}

Of all studies included in this review, six used body postural assessment $5,7,9,14,16,17$, five assessed only craniocervical posture and shoulders ${ }^{6,12,19,21,23}$, and all others assessed only craniocervical and/or cervical posture $^{8,10,11,13,15,18,50-52}$.

\section{Sample size, posture method assessment, and examiner blinding}

Sample size was calculated in only three studies $^{19,21,49}$ (Table 2). Of the studies that analyzed only craniocervical posture, six studies described the use of assessment by radiographic analyses ${ }^{10,13,15,18,49,51}$, six studies used the photographic method ${ }^{6,11,12,19,21,50}$, and two described the use of the both radiographic and photographic methods ${ }^{8,22}$ (Tables 3 and 4).

Only six studies assessed global body posture $^{5,7,9,14,16,17}$. Five used the visual inspection method $^{5,9,14,16,17}$, one used the quantified photographic $\operatorname{method}^{7}$, and one used the photographic method with qualitative analysis ${ }^{14}$ (Table 4). Eleven studies described examiner blinding to assess body or craniocervical posture ${ }^{5,8,9,13,15,16,18,19,21,22,51}$ (Tables 3 and 4).

Considering the reliability of the body posture measures, seven studies did not provide this information accurately $y^{5,6,11,12,17,18,50}, 11$ reported good levels of reliability among the repeated measures $^{7-10,13,15,19,21,22,51,52}$, and one study reported poor reliability ${ }^{16}$ (Tables 3 and 4).

Only one of the studies included in this review mentioned the validity of the measures employed for postural assessment ${ }^{22}$, however the reference that 
certified the method validity was probably incorrect ${ }^{54}$ The authors did not answer the e-mail to clarify this possible error.

Of the six studies using global body posture, the standardization for posture analysis and analysis method was appropriately described in three studies $^{7,14,16}$. The photogrammetry method was used by two studies s.14 $^{7}$ and a previously described method combining photographic and visual inspection was used in one study ${ }^{16}$ (Table 4).

\section{Postural changes in TMD}

Body posture changes in the group of patients with TMD in relation to a control group was verified in 13 studies $67,9,10,12,16-19,21,50-52$ (Tables 3 and 4). Among the studies that assessed craniocervical posture $(n=20)$, 10 studies reported misalignment in the TMD gro up $^{6,7,9,10,12,17,19,21,50,52}$. Three studies verified alterations in FHP angle ${ }^{6,12,50}$ and two studies ${ }^{19,21}$ used another angle measurement (eye-tragus-horizontal angle). In all of the studies, head protrusion or extension was observed. Considering the five studies that performed specific measurements of the cervical spine $^{8,14,18,22,51}$, changes of this segment were observed in two studies ${ }^{18,51}$. Upper cervical spine flexion and hyperlordosis were reported by De Farias Neto et al. ${ }^{18}$ and cervical spine straightening by D'Áttilio et al. ${ }^{51}$ (Tables 3 and 4).

Of the studies that verified shoulder postural changes $^{5-7,9,12,14,16}$, four studies verified posture changes in this segment in the TMD group ${ }^{6,9,12,16}$. The misalignments were: greater shoulder extension ${ }^{6}$, assymetrical shoulders and abducted scapula ${ }^{9}$, shoulder protrusion ${ }^{12}$, and elevated shoulder ${ }^{16}$ (Tables 3 and 4).

Among the six studies that assessed pelvic posture, four studies ${ }^{7,9,16,17}$ verified pelvic misalignments in the frontal plane ${ }^{7}$, iliac crest $^{9}$, muscle chain ${ }^{16}$, and posterior rotation ${ }^{17}$ (Tables 3 and 4). Spinal misalignments were identified by two of the five studies that included this topic in the postural assessment ${ }^{5,9,14,16,17}$ : greater thoracic kyphosis and lumbar hyperlordosis ${ }^{9}$ and kyphosis straightening and lumbar hyperlordosis ${ }^{17}$ (Table 4). However, of the studies that were classified as moderate or strong quality, Armijo-Olivo et al. ${ }^{19,21}$ reported greater head extension and D'Áttilio et al. ${ }^{51}$ observed cervical spine straightening.

\section{Postural changes in TMD subtypes}

Of the five studies that included a group of patients with myogenous $\mathrm{TMD}^{5,8,19,21,22}$, two found body posture misalignments (head extension) in the TMD group in relation to the control group or mixed TMD group ${ }^{19,21}$. Both studies were classified as strong according to the adopted quality criteria applied (Tables 3 and 4).

Concerning arthrogenous TMD, four studies verified body posture changes in the TMD group in relation to the control group or another TMD group ${ }^{12,17,51,52}$, and three did not report craniocervical postural changes ${ }^{8,11,15}$. Only the study by D'Áttilio et al. ${ }^{51}$ was classified as moderate quality. The authors reported cervical spine straightening (Tables 3 and 4).

Among the studies that included a group of mixed TMD patients in relation to a control group or another TMD group ${ }^{6-10,16,18,19,21,22,50}$, seven reported body posture alterations $\mathbf{s}^{6,7,9,10,16,18,50}$. Only two studies ${ }^{19,21}$ were classified as strong quality and they did not report body posture alterations for the mixed TMD group (Tables 3 and 4), however in both studies this group had to have a diagnosis of myiogenous TMD according to the RDC/TMD but not a diagnosis of arthrogenous TMD according to these criteria, only signs and symptoms.

\section{Discussion}

The purpose of this systematic review was to identify the level of scientific evidence for the association between TMD and body and/or craniocervical posture misalignment. The quality criteria adopted for review of the studies have been described in previous studies ${ }^{20}$ and the agreement between the reviewers for the methodological classification of the studies was high (kappa: 0.91), demonstrating that the review process was considered reliable.

This systematic review considered global body posture misalignment. Regarding the three systematic reviews on the subject, two of them considered craniocervical posture only ${ }^{20,26}$ and the other presented records of static posture that were analyzed together with records of balance - static posturography ${ }^{25}$. Moreover, these authors ${ }^{25}$ disregard studies about craniocervical posture. Postural assessments aimed at finding postural deviations are routinely made by physical therapists to analyze body segments in the static position and do not include the assessment of oscillations that must be considered as balance assessment.

A significant number of the studies found in the literature and included in this review $(n=14)$ considered only the assessment of the head 
segment $t^{6,8,10-13,15,18,19,21,22,50-52}$. This aspect is probably related to the fact that it is easier to perform the procedure in the craniocervical segment, since the individual does not need to be evaluated in bathing clothes, and moreover because the radiographic procedure commonly employed in dentistry only considers the head and cervical spine, and it does not enable the analysis of global body posture. On the other hand, this aspect disregards posture assessment as a whole and it is possible that head changes are related to distal changes, since the connection between the muscles through the muscular chains would facilitate the emergence of postural compensation in other body segments ${ }^{23}$.

\section{Main findings and TMD subtypes}

This review demonstrated that there is evidence for craniocervical postural change (i.e. head extension) in patients with myogenous TMD in relation to controls. Of the five studies that included a group of patients with myogenous $\mathrm{TMD}^{5,8,19,21,22}$, two studies were classified as strong according to the quality criteria employed and verified only craniocervical posture changes in TMD in relation to a control group or a mixed TMD group ${ }^{19,21}$

Considering body posture misalignment in arthrogenous TMD, only the study of D'Attilio et al. ${ }^{51}$ was classified as moderate according to the criterion quality adopted. Therefore, it was observed that there was moderate evidence and risk of bias for the presence of cervical posture misalignment (i.e.cervical spine straightening) in patients with arthrogenous TMD, diagnosed by MRI, in relation to a control group.

Considering studies involving patients with mixed TMD, only two studies ${ }^{19,21}$ obtained a strong classification according to the quality criteria adopted and they did not report body postural misalignment for the mixed TMD group. One of the reasons for the absence of evidence of body postural misalignment in mixed TMD patients compared to myogenous and arthrogenous patients could be related to the sample selection adopted ${ }^{19,21}$. The patients should have a diagnosis of myogenous TMD according to the RDC/TMD associated with signs and symptoms of arthrogenic TMD. In this way, all of the patients must have a diagnosis of myogenous TMD, but not of arthrogenous TMD. It is possible that the "mixed TMD group" could not fill the criteria for an arthrogenous TMD diagnosis, since signs and symptoms of arthrogenous complaints have commonly been observed in the population ${ }^{55}$. Hence, there is no evidence that patients with mixed TMD (i.e. with myogenous TMD diagnosis and signs and symptoms of arthrogenous TMD) did not have body or craniocervical misalignment in relation to individuals without TMD or myogenous TMD.

D'Atillio et al. ${ }^{51}$ demonstrated cervical spine straightening in arthrogenous TMD patients and received a moderate evidence level classification. However, D'Atillio et al. ${ }^{51}$ used radiographic analysis to assess cervical spine misalignment and Armijo-Olivo et al. ${ }^{19,21}$ verified only head and cervical/head posture. In this way, it is possible that in patients with arthrogenous TMD, cervical spine misalignment could be more common, and in patients with myogenous TMD disorders, head posture misalignment could be more common. It could explain the absence of body posture misalignment for mixed TMD group described by Armijo-Olivo et al. ${ }^{19,21}$.

However, all of these theories are speculative and the attention should focus on the need for future studies to include a large sample size, control the diagnostic criteria for mixed and arthrogenous groups, and consider not only photographic records but also radiographic procedures to analyze the cervical spine more specifically. Two studies assessed body posture by both photography and radiography ${ }^{8,22}$, however the major flaw of these papers was their limited sample size. ArmijoOlivo et al. ${ }^{19}$ described a minimum of 50 subjects ( $\alpha=0.05, \beta=0.20$, power $=80 \%$, and effect size of 0.5 ) to assess posture by photographic records.

Global body postural misalignment in the group of TMD patients was verified in four studies ${ }^{7,9,16,17}$. All studies obtained a weak classification. Aspects such as absence of blinding of the examiner ${ }^{7,17}$, failure in sample eligibility criterion ${ }^{9,16}$, and poorly described or undescribed reliability of the method ${ }^{5,16,17}$ were some of the characteristics that did not support the evidence of possible global body postural changes in arthrogenous, myogenous or mixed TMD groups in relation to a control group.

As contribution for future publications, the authors recommend effect size and power analysis, a more controlled design, appropriate description of reliability/validity of the measures (specifically for global body postural assessment), blinding of the examiners, random sampling, and, eligibility criteria of patients with control of subtypes of TMD according to well stablished criteria. 


\section{Conclusion}

The main contributions of the present review are the following: there is evidence and low risk of bias that patients with myogenous TMD have craniocervical postural misalignment. For the arthrogenous TMD group, moderate evidence for cervical spine alterations was observed. Moreover, there was no evidence in the literature for the absence of craniocervical posture misalignment in mixed TMD patients and for global body posture misalignment in TMD. The poor methodological quality of the studies considered in this revision, especifically for body postural misalignment could be the explanation for the weak evidence observed.

\section{References}

1. Dworkin SF, LeResche L. Research Diagnostic Criteria for temporomandibular disorders: review, criteria, examinations and specifications, critique. J Craniomandib Disord. 1992;6(4):301-55. PMID: 1298767.

2. Suvinen TI, Reade PC, Kemppainen P, Könönen M, Dworkin SF. Review of aetiological concepts of temporomandibular pain disorders: towards a biopsychosocial model for integration of physical disorder factors with psychological and psychosocial illness impact factors. Eur J Pain. 2005;9(6):613-33. http://dx.doi.org/10.1016/j. ejpain.2005.01.012. PMid:15978854

3. Look JO, Schiffman EL, Truelove EL, Ahmad M. Reliability and validity of Axis I of the Research Diagnostic Criteria for Temporomandibular Disorders (RDC/TMD) with proposed revisions. J Oral Rehabil. 2010;37(10):74459. http://dx.doi.org/10.1111/j.1365-2842.2010.02121.x. PMid:20663019

4. Schiffman EL, Truelove EL, Ohrbach R, Anderson GC, John MT, List T, et al. The Research Diagnostic Criteria for Temporomandibular Disorders. I: overview and methodology for assessment of validity. J Orofac Pain. 2010;24(1):7-24. PMid:20213028.

5. Darlow LA, Pesco J, Greenberg MS. The relationship of posture to myofascial pain dysfunction syndrome. J Am Dent Assoc. 1987;114(1):73-5. PMid:3468171.

6. Braun BL. Postural differences between asymptomatic men and women and craniofacial pain patients. Arch Phys Med Rehabil. 1991;72(9):653-6. PMid:1859260.

7. Zonnenberg AJ, Van Maanen CJ, Oostendorp RA, Elvers JW. Body posture photographs as a diagnostic aid for musculoskeletal disorders related to temporomandibular disorders (TMD). Cranio. 1996;14(3):225-32. PMid:9110614.

8. Visscher CM, De Boer W, Lobbezoo F, Habets LLMH, Naeije M. Is there a relationship between head posture and craniomandibular pain? J Oral Rehabil. 2002;29(11):10306. http://dx.doi.org/10.1046/j.1365-2842.2002.00998.x. PMid: 12453255

9. Nicolakis P, Nicolakis M, Piehslinger E, Ebenbichler G, Vachuda M, Kirtley C, et al. Relationship between craniomandibular disorders and poor posture. Cranio. 2000;18(2):106-12. PMid:11202820.

10. Sonnesen L, Bakke M, Solow B. Temporomandibular disorders in relation to craniofacial dimensions, head posture and bite force in children selected for orthodontic treatment. Eur J Orthod. 2001;23(2):179-92. http://dx.doi. org/10.1093/ejo/23.2.179. PMid:11398555

11. Hackney J, Bade D, Clawson A. Relationship between forward head posture and diagnosed internal derangement of the temporomandibular joint. J Orofac Pain. 1993;7(4):386-90. PMid:8118442.

12. Evcik D, Aksoy O. Relationship between head posture and temporomandibular dysfunction syndrome. J Musculoskeletal Pain. 2004;12(2):19-24. http://dx.doi. org/10.1300/J094v12n02_03.

13. Munhoz WC, Marques AP, Siqueira JT. Radiographic evaluation of cervical spine of subjects with temporomandibular joint internal disorder. Braz Oral Res. 2004;18(4):283-9. http://dx.doi.org/10.1590/S180683242004000400002. PMid:16089257

14. Munhoz WC, Marques AP, de Siqueira JT. Evaluation of body posture in individuals with internal temporomandibular joint derangement. Cranio. 2005;23(4):269-77. PMid:16353467.

15. Matheus RA, Ramos-Perez FM, Menezes AV, Ambrosano GM, Haiter-Neto F, Bóscolo FN, et al. The relationship between temporomandibular dysfunction and head and cervical posture. J Appl Oral Sci. 2009;17(3):204-8. http://dx.doi.org/10.1590/S1678-77572009000300014. PMid:19466252

16. Munhoz WC, Marques AP. Body posture evaluations in subjects with internal temporomandibular joint derangement. Cranio. 2009;27(4):231-42. PMid:19891257.

17. Saito ET, Akashi PMH, Sacco IC. Global body posture evaluation in patients with temporomandibular joint disorder. Clinics (Sao Paulo). 2009;64(1):35-9. http://dx.doi. org/10.1590/S1807-59322009000100007. PMid:19142549

18. de Farias Neto JP, de Santana JM, de Santana-Filho VJ, Quintans-Junior LJ, de Lima Ferreira AP, Bonjardim LR. Radiographic measurement of the cervical spine in patients with temporomandibular dysfunction. Arch Oral Biol. 2010;55(9):670-8. http://dx.doi.org/10.1016/j. archoralbio.2010.06.002. PMid:20591410

19. Armijo-Olivo S, Warren S, Fuentes J, Magee DJ. Clinical relevance vs. statistical significance: Using neck outcomes in patients with temporomandibular disorders as an example. Man Ther. 2011;16(6):563-72. http://dx.doi. org/10.1016/j.math.2011.05.006. PMid:21658987

20. Olivo SA, Bravo J, Magee DJ, Thie NM, Major PW, FloresMir C. The association between head and cervical posture and temporomandibular disorders: a systematic review. J Orofac Pain. 2006;20(1):9-23. PMid:16483016.

21. Armijo-Olivo S, Rappoport K, Fuentes J, Gadotti IC, Major PW, Warren S, et al. Head and cervical posture in patients with temporomandibular disorders. J Orofac Pain. 2011;25(3):199-209. PMid:21837287.

22. Iunes DH, Carvalho LCF, Oliveira AS, BevilaquaGrossi D. Craniocervical posture analysis in patients with temporomandibular disorder. Rev Bras 
Fisioter. 2009;13(1):89-95. http://dx.doi.org/10.1590/ S1413-35552009005000011.

23. Bonetti F, Curti S, Mattioli S, Mugnai R, Vanti C, Violante FS, et al. Effectiveness of a 'Global Postural Reeducation' program for persistent low back pain: a nonrandomized controlled trial. BMC Musculoskelet Disord. 2010;11(1):285. http://dx.doi.org/10.1186/1471-2474-11285. PMid:21162726

24. Fernández-de-Las-Peñas C, Alonso-Blanco C, AlguacilDiego IM, Miangolarra-Page JC. One-year follow-up of two exercise interventions for the management of patients with ankylosing spondylitis: a randomized controlled trial. Am J Phys Med Rehabil. 2006;85(7):559-67. http://dx.doi. org/10.1097/01.phm.0000223358.25983.df. PMid:16788386

25. Perinetti G, Contardo L. Posturography as a diagnostic aid in dentistry: a systematic review. J Oral Rehabil. 2009;36(12):922-36. http://dx.doi.org/10.1111/j.13652842.2009.02019.x. PMid:19878440

26. Rocha CP, Croci CS, Caria PHF. Is there relationship between temporomandibular disorders and head and cervical posture? A systematic review. J Oral Rehabil. 2013;40(11):875-81. http://dx.doi.org/10.1111/joor.12104. PMid:24118029

27. Huggare JA, Raustia AM. Head posture and cervicovertebral and craniofacial morphology in patients with craniomandibular dysfunction. Cranio. 1992;10(3):173-7, discussion 178-9. PMid:1423679.

28. Wright EF, Domenech MA, Fischer JR Jr. Usefulness of posture training for patients with temporomandibular disorders. J Am Dent Assoc. 2000;131(2):202-10. http://dx.doi.org/10.14219/jada.archive.2000.0148. PMid:10680388

29. Moher D, Liberati A, Tetzlaff J, Altman DG, PRISMA Group. Preferred reporting items for systematic reviews and meta-analyses: the PRISMA statement. Int J Surg. 2010;8(5):336-41. http://dx.doi.org/10.1016/j. ijsu.2010.02.007. PMid:20171303

30. McNeely ML, Torrance G, Magee DJ. A systematic review of physiotherapy for spondylolysis and spondylolisthesis. Man Ther. 2003;8(2):80-91. http://dx.doi.org/10.1016/ S1356-689X(02)00066-8. PMid:12890435

31. McNeely ML, Armijo Olivo S, Magee DJ. A systematic review of the effectiveness of physical therapy interventions for temporomandibular disorders. Phys Ther. 2006;86(5):710-25. PMid:16649894.

32. Ferrão MIB, Traebert J. Prevalence of temporomandibular disfunction in patients with cervical pain under physiotherapy treatment. Fisioter Mov. 2008;21(4):63-70.

33. Augustine C, Makofsky HW, Britt C, Adomsky B, Deshler JM, Ramirez P, et al. Use of the Occivator for the correction of forward head posture, and the implications for temporomandibular disorders: a pilot study. Cranio. 2008;26(2):136-43. PMid:18468273.

34. Strini PJSA, Machado NAG, Gorreri MC, Ferreira AF, Sousa GC, Fernandes Neto AJ. Postural evaluation of patients with temporomandibular disorders under use of occlusal splints. J Appl Oral Sci. 2009;17(5):539-43. http://dx.doi. org/10.1590/S1678-77572009000500033. PMid:19936539

35. Maluf SA, Moreno BGD, Crivello O, Cabral CMN, Bortolotti G, Marques AP. Global postural reeducation and static stretching exercises in the treatment of myogenic temporomandibular disorders: a randomized study. J Manipulative Physiol Ther. 2010;33(7):500-7. http://dx.doi. org/10.1016/j.jmpt.2010.08.005. PMid:20937428

36. Paris SV. Cervical symptoms of forward head posture. Top Geriatr Rehabil. 1990;5(4):11-9. http://dx.doi. org/10.1097/00013614-199007000-00006.

37. Ciancaglini R, Colombo-Bolla G, Gherlone EF, Radaelli G. Orientation of craniofacial planes and temporomandibular disorder in young adults with normal occlusion. J Oral Rehabil. 2003;30(9):878-86. http://dx.doi.org/10.1046/ j.1365-2842.2003.01070.x. PMid:12950968

38. Talebian S, Otadi K, Ansari NN, Hadian MR, Shadmehr A, Jalaie S. Postural control in women with myofascial neck pain. J Musculoskeletal Pain. 2012;20(1):25-30. http:// dx.doi.org/10.3109/10582452.2011.635847.

39. Cuccia AM, Carola C. The measurement of craniocervical posture: a simple method to evaluate head position. Int J Pediatr Otorhinolaryngol. 2009;73(12):1732-6. http://dx.doi. org/10.1016/j.ijporl.2009.09.011. PMid:19786307

40. Ries LGK, Bérzin F. Analysis of the postural stability in individuals with or without signs and symptoms of temporomandibular disorder. Braz Oral Res. 2008;22(4):378-83. http://dx.doi.org/10.1590/S180683242008000400016. PMid:19148396

41. Armijo-Olivo S, Silvestre RA, Fuentes JP, da Costa BR, Major PW, Warren S, et al. Patients with temporomandibular disorders have increased fatigability of the cervical extensor muscles. Clin J Pain. 2012;28(1):55-64. http:// dx.doi.org/10.1097/AJP.0b013e31822019f2. PMid:21677569

42. Gonzalez HE, Manns A. Forward head posture: its structural and functional influence on the stomatognathic system, a conceptual study. Cranio. 1996;14(1):71-80. PMid:9086879.

43. Amantéa DV, Novaes AP, Campolongo GD, Barros TP. The importance of the postural evaluation in patients with temporomandibular joint dysfunction. Acta Ortop Bras. 2004;12(3):155-9.

44. Hibi H, Ueda M. Body posture during sleep and disc displacement in the temporomandibular joint: a pilot study. J Oral Rehabil. 2005;32(2):85-9. http://dx.doi. org/10.1111/j.1365-2842.2004.01386.x. PMid:15641972

45. Cuccia A, Caradonna C. The relationship between the stomatognathic system and body posture. Clinics (Sao Paulo). 2009;64(1):61-6. http://dx.doi.org/10.1590/S180759322009000100011. PMid:19142553

46. Robson FC. The clinical evaluation of posture: relationship of the jaw and posture. Cranio. 2001;19(2):144. PMid:11842865.

47. Perinetti G. Correlations between the stomatognathic system and body posture: biological or clinical implications? Clinics (Sao Paulo). 2009;64(2):77-8. http://dx.doi.org/10.1590/S1807-59322009000200002. PMid:19219310

48. Pradham NS, White GE, Mehta N, Forgione A. Mandibular deviations in TMD and non-TMD groups related to eye dominance and head posture. J Clin Pediatr Dent. 2001;25(2):147-55. PMid:11314215. 
49. Shiau YY, Chai HM. Body posture and hand strength of patients with temporomandibular disorder. Cranio. 1990;8(3):244-51. PMid:2083432.

50. Lee WY, Okeson JP, Lindroth J. The relationship between forward head posture and temporomandibular disorders. J Orofac Pain. 1995;9(2):161-7. PMid:7488986.

51. D'Attilio M, Epifania E, Ciuffolo F, Salini V, Filippi MR, Dolci M, et al. Cervical lordosis angle measured on lateral cephalograms; findings in skeletal class II female subjects with and without TMD: a cross sectional study. Cranio. 2004;22(1):27-44. http://dx.doi.org/10.1179/crn.2004.005. PMid:14964336

52. Ioi H, Matsumoto R, Nishioka M, Goto TK, Nakata S, Nakasima A, et al. Relationship of TMJ osteoarthritis / osteoarthrosis to head posture and dentofacial morphology. Orthod Craniofac Res. 2008;11(1):8-16. http://dx.doi. org/10.1111/j.1601-6343.2008.00406.x. PMid:18199075

53. Visscher CM, Lobbezoo F, de Boer W, van der Zaag J, Verheij JG, Naeije M. Clinical tests in distinguishing between persons with or without craniomandibular or cervical spinal pain complaints. Eur J Oral Sci. 2000;108(6):47583. http://dx.doi.org/10.1034/j.1600-0722.2000.00916.x. PMid:11153922

54. Streiner D, Norman G. Validity. In: Streiner D, Norman G (eds). Health measurements scales. Oxford: Oxford University; 2004. p. 172-93.

55. Manfredini D, Arveda N, Guarda-Nardini L, Segù M, Collesano V. Distribution of diagnoses in a population of patients with temporomandibular disorders. Oral Surg Oral Med Oral Pathol Oral Radiol. 2012;114(5):e35-41. PMid:22921443.

56. Viikari-Juntura E. Interexaminer reliability of observations in physical examinations of the neck. Phys Ther. 1987;67(10):1526-32. PMid:3659137.

57. Helkimo M. Studies on function and dysfunction of the masticatory system. II. Index for anamnestic and clinical dysfunction and occlusal state. Sven Tandlak Tidskr. 1974;67(2):101-21. PMid:4524733.

58. Muir CB, Goss AN. The radiologic morphology of asymptomatic temporomandibular joints. Oral Surg Oral Med Oral Pathol. 1990;70(3):349-54. http://dx.doi. org/10.1016/0030-4220(90)90154-K. PMid:2216365

59. Kendall FP, McCreary EK, Provance PG. Muscles: Testing and Function. Baltimore, MD: Williams \& Wilkins; 1993.

\section{Correspondence \\ Thaís Cristina Chaves}

Universidade de São Paulo

Faculdade de Medicina de Ribeirão Preto

Departamento de Neurosciências e Ciências do Comportamento Avenida dos Bandeirantes, 3900

CEP 14049-900, Ribeirão Preto, SP, Brasil

e-mail: chavestc@fmrp.usp.br 